\title{
Pragmatismo e Razão Comunicacional: uma contribuição ao Aprendizado Educacional
}

\section{Pragmatism and Comumunicative Reason: a contribution to Educational Learning}

\section{Dagmar Manieri}

Professor doutor na Universidade Federal do Tocantins, Araguaína, Tocantins, Brasil. dagmarmanieri@uft.edu.br - https://orcid.org/0000-0001-5082-3599

Recebido em 13 de junho de 2020

Aprovado em 11 de agosto de 2020

Publicado em 28 de outubro de 2020

\section{RESUMO}

O objetivo desse artigo é um estudo sobre as potencialidades educativas da razão comunicativa. Desde o surgimento do pragmatismo, presencia-se um grupo de pensadores que questiona a prática fundamentada na razão centrada no sujeito. Iniciada no ambiente de confronto com o saber advindo da autoridade religiosa, a razão lluminista centrada no sujeito se ampara na certeza da razão universal, presente nos sujeitos. Com o pragmatismo há novas formas de racionalidade, com destaque para um tipo de razão que se forma nas relações intersubjetivas. Em Habermas, particularmente, a razão comunicativa promove novas concepções sobre a "verdade" e o "conhecimento". Entendida no campo educacional, a razão comunicativa resulta em um novo processo de aprendizado. Palavras-chave: Pragmatismo; Razão comunicativa; lluminismo; Educação; Aprendizado.

\begin{abstract}
The aim of this article is to study the educational potential of communicative reason. Since the emergence of pragmatism, there has been a group of thinkers who question the practice based on reason centered on the subject. Initiated in an environment of confrontation with knowledge arising from religious authority, the Enlightenment reason centered on the subject is based on the certainty of universal reason, present in the subjects. With pragmatism there are new forms of rationality, with emphasis on a type of reason that is formed in intersubjective relations. In Habermas, in particular, communicative reason promotes new conceptions about "truth" and "knowledge". Understood in the educational field, communicative reason results in a new learning process. Keywords: Pragmatism; Communicative Reason; Enlightenment; Education; Learning.
\end{abstract}

\section{Introdução}

Há no campo do pragmatismo uma relação com o saber que comporta uma série de objeções ante a tradição filosófica. William James, por exemplo, comenta sobre a "vacuidade do filosofar realista". Para ele, o universo é um todo complexo e aberto; mas "o racionalismo faz sistemas, e os sistemas devem ser fechados" (JAMES, 1967, p. 36). É em contraponto a algumas correntes filosóficas, como o racionalismo, que o pragmatismo apresenta uma nova abordagem do saber. 
$\mathrm{Na}$ verdade, os primeiros pragmatistas como Charles Peirce e William James rejeitam o intelectualismo abstrato ou fundado em razões a priori. Como acentua James, o pragmatismo não busca "princípios firmados" ou "sistemas fechados", com pretensões ao absoluto ou às origens. James insiste na ideia de que uma teoria só tem valor se ela for útil; assim, há no pragmatismo uma nova postura diante do conhecimento. Não se prioriza a questão da "verdade", mas sua utilidade na prática social. Neste caso, ainda na concepção de James, o pragmatismo é mais flexível se comparado às outras correntes filosóficas. Nesta corrente de pensamento, os "recursos são ricos e intermináveis"; isto ocorre, pois nele há uma postura epistemológica aberta e relativa ante os problemas do saber. Na concepção de Richard Rorty (1988), essa revisão na "postura epistemológica" equivale a um apreço à hermenêutica. Como interpreta Maria Dazzani, a hermenêutica em Rorty equivale a "uma conversação onde nunca se perde a esperança de acordo" (DAZZANI, 2000, p. 52).

Por isso a necessidade de, inicialmente, se formar (no educando) um espírito crítico ante as "verdades" ensinadas. De certa forma, isto corresponde a uma postura condizente ao campo pragmático. O Fedro, de Platão (2011), pode servir como um bom exemplo para se ilustrar a importância do senso crítico. O jovem Fedro sente-se admirado pelo discurso (sobre o amor) de Lísias. Platão, através de seu personagem de Sócrates, mostra ao jovem entusiasta que ele vive uma ilusão (apáte), interpelado pelo poder discursivo do sofista. Isto ocorre porque Fedro não tinha promovido uma educação dialética. Platão indica a verdadeira educação; ela deve se iniciar pela prática da refutação (élenkhos). Por isso, na interpretação de Paviani, só o dialético "sabe perceber uma ideia única presente numa pluralidade de ideias" (PAVIANI, 2001, p. 59).

No pragmatismo a refutação não se envereda em busca de verdades inteligíveis, como no platonismo; muito menos segue na senda do ceticismo. Arcesilau, o líder cético da Academia, comenta que "a ilusão de saber" deve ser "submetida ao élenkhos purificador que demonstra sua ilusão, para alcançar coerentemente a epokhé (suspensão do juízo)" (BOLZANI FILHO, 2013, p. 89).

Nesse intento, este artigo visualiza uma das possibilidades da prática educativa amparada no pragmatismo; daí a importância da filosofia ao mostrar (através do pragmatismo) o surgimento da razão comunicativa como categoria mediadora para a "apreensão" do conhecimento. Tal categoria é condizente com um ambiente democrático, bem como facilitadora de uma nova postura diante do saber compartilhado no espaço escolar.

\section{Razão centrada no sujeito e razão comunicativa}

Quando nos referimos à razão comunicativa, há de forma implícita uma crítica à razão moderna. Ela é comumente denominada de razão centrada no sujeito. Tal concepção de razão expressa uma determinada representação sobre o homem; para tanto, deve-se atentar para dois fenômenos históricos. O primeiro se refere ao extenso período de predomínio da fé cristã que exerceu uma espécie de hegemonia cultural; o segundo, ao nascimento da ciência natural moderna e que inaugura uma nova relação do homem com a natureza. 
Segundo esses dois fenômenos culturais indicados acima, há de se destacar as figuras de Galileu Galilei e René Descartes. No primeiro, além de seu trabalho como cientista, temos a divulgação (compreendida como trabalho de difusão cultural) de uma versão do universo físico (teoria heliocêntrica de Copérnico) que se contrapõe à visão tradicional (geocêntrica) da Igreja Católica. Ludovico Geymonat cita uma carta endereçada ao Santo Ofício, na qual o delator confidencia: "Galileu semeou nesta cidade [Florença] opiniões pouco católicas, (...)" (Apud GEYMONAT, 1997, p. 216). Como enfatiza o próprio Geymonat, Galileu não foi só um grande cientista; em várias obras presencia-se um "agudo experimentador, com sua força de corajoso inovador da cultura" (GEYMONAT, 1997, p. 140). No exemplo de Saggiatore, Geymonat enfatiza que "é uma obra fascinante de propaganda cultural, (...)" (GEYMONAT, 1997, p. 140).

René Descartes, assim como Galileu, representa a entrada no mundo moderno. Seu cogito é a própria expressão da confiança na razão humana. $O$ anseio por um conhecimento seguro está presente de forma marcante no filósofo francês. No Discurso do método, ele comenta que procura uma ciência com bons fundamentos; uma certeza "que pudesse existir em mim próprio, ou então, no grande livro do mundo, (...)" (DESCARTES, 1989, p. 37). O filósofo aponta a segurança na luz da razão (Iumine rationis). Miguel Spinelli cita uma passagem de Descartes: "A minha dúvida se aplica somente às coisas que existem fora de mim, enquanto a minha certeza concerne à minha dúvida e a mim mesmo" (Apud SPINELLI, 2013, p. 311). Assim, o próprio ato de duvidar faz parte do método de se conhecer de forma clara e distinta. Por isso é preciso um passo além da dúvida, pois "o conhecer é perfeição maior do que o duvidar (...)" (DESCARTES, 1989, p. 57). No fundo, em Descartes há a certeza desta "luz" da razão que discerne entre "o verdadeiro do falso" (1989, p. 52); ela provém da "capacidade de nossas almas de receber de Deus [entenda-se, a Natureza] um conhecimento intuitivo" (Apud SPINELLI, 2013, p. 309). Esta passagem das Lettres, citada por Spinelli, mostra que o cogito possui um conteúdo "dedutível de um conhecimento intuitivo". Neste caso, o cogito se identifica às "verdades eternas"; para Spinelli, são "verdades que só têm existência no pensamento, e que, em relação a elas (é o que admite), a dúvida não recai” (SPINELLI, 2013, p. 310).

Por isso os séculos XVII e XVIII marcam uma época em que se presencia o conflito entre a fé católica e razão lluminista, tão bem expressa na literatura de Flaubert, especialmente, em Madame Bovary (2016) nas figuras do padre Bournisien e do farmacêutico, Homais.

É em relação a essa razão centrada no sujeito que o pragmatismo intenta uma nova forma de racionalidade. Richard Rorty em Filosofia como política cultural (2009) comenta sobre a importância da teoria de Habermas. O filósofo norte-americano enfatiza que neste último, a razão comunicativa não representa mais "um dom humano natural", mas uma faculdade em íntima relação com as práticas sociais. Para Rorty, a razão centrada no sujeito não leva em consideração a conversação; na razão lluminista, háo intuito de se esquivarda "opinião e dirigir-se diretamente ao conhecimento". Já a razão comunicativa é descrita, desta forma, por Rorty: 
Substituir a razão centrada no sujeito pela racionalidade comunicativa é ver a verdade como aquilo que provavelmente resultará de uma conversação livre e imaginativa. É pensar o conhecimento como a realização de um consenso, antes de como um estado mental que goza de uma relação mais estreita com a realidade do que com a opinião (RORTY, 2009, p. 136).

$\mathrm{Na}$ nova postura pedagógica de orientação pragmática, há essa intenção de rejeitar a razão centrada no sujeito. Em Democracia e educação, John Dewey afirma que "todo indivíduo cresceu, e sempre deve crescer, em um meio social” (DEWEY, 2007, p. 53). Por isso, termos como "Eu" e "conhecimento" recebem um tratamento mais sociológico: "O Eu alcança inteligência, na medida em que o conhecimento das coisas está encarnado na vida que o rodeia; o Eu não é uma mente separada, construindo novos conhecimentos por conta própria" (DEWEY, 2007, p. 53).

Dewey não rejeita o conhecimento objetivo; ele enfatiza a importância do estado da dúvida (ou incerteza). Só assim, o conhecimento objetivo pode adquirir significado e ser "reorganizado". Dewey confidencia que isto não é uma tarefa fácil, pois se devem reconhecer dois momentos. Primeiro, aceitar que há um "individualismo intelectual legítimo": ele é criativo e promove o progresso do conhecimento. Já o segundo momento corresponde em se compreender o individualismo em um contexto social:

Suas raízes [do individualismo] encontram-se na noção de que a consciência de cada pessoa é completamente privada, um continente fechado em si mesmo, intrinsecamente apartado das ideias, desejos e propósitos de qualquer outro indivíduo. Contudo, quando os homens agem, eles o fazem em um mundo público e comum (DEWEY, 2007, p. 56,57$)$.

Passagem importante, pois enfatiza que a educação deve visar essas duas dimensões: o individualismo intelectual e uma forma de consciência coletiva (o "público", o "comum"). No ambiente educacional deve haver um espaço para a criatividade, bem como outro para as interações. Há a importância de no espaço escolar se cultivar uma "razão comum" que se diferencia do racionalismo lluminista. Na linguagem de George Mead, a importância da participação cooperativa em atividades comuns. Aqui, a importância de outro pragmatista que desenvolve uma reflexão importante sobre a formação humana fundamentada no interacionismo simbólico. Como na interpretação de Cledes Casagrande, Mead nos mostrou que através do "uso da linguagem e de símbolos significantes, o indivíduo internaliza as atitudes do seu grupo social. Adota, em relação a si mesmo, a mesma atitude que a comunidade adota em relação a ele" (CASAGRANDE, 2016, p. 382).

Já para Dewey, na razão Iluminista há uma "natureza formal e vazia, por considerar a razão algo completo em si mesmo (...)" (DEWEY, 2007, p. 59). Em Dewey, a razão comunicativa surge como "cooperação intelectual"; a escola deve propiciar um ambiente que seja comum os "argumentos", a "discussão" e a "persuasão" (DEWEY, 2007, p. 59). Por isso, na apreciação do educador pragmatista, o aprendizado requer um tipo de educando 
ativo: "O que o aluno já sabe só pode ser ampliado e retificado por meios de observação, reflexão e ajustamento próprios e, então, pelo teste de suas ideias" (DEWEY, 2007, p. 65).

Neste caso, tanto Dewey quanto Mead, concedem a importância de práticas comuns no ambiente educacional. Em Dewey, experiências educacionais que favorecem a aprendizagem; em Mead, situações educacionais que formam um "mim" (me) no processo de socialização.

\section{Educação e razão comunicativa em Habermas}

A proposta de razão comunicativa em Jürgen Habermas foi influenciada pelos trabalhos de George Mead. Na medida em que Habermas acentua a importância da razão comunicativa, pode-se pensar na possibilidade do surgimento de uma nova forma de consciência que tem sua gênese nas interações comunicativas. Então, trata-se de um estudo (não como no paradigma da "consciência" na tradição filosófica) sobre uma forma de prática social na qual se rejeita o sujeito concebido de forma isolada.

Em relaçãoao pensamento deHabermas, Flávio Siebeneichlerevidencia que nesteúltimo há um novoparadigma filosófico. Osujeito é concebidoatravés da relação comunicativa, comoumser capaz de fala; assim, Habermas desenvolve uma teoria do "enfoque performativo do entendimento intersubjetivo entre sujeitos capazes de falar e de agir" (SIEBENEICHLER, 2003, p. 62)

Nesse meio comunicativo observa-se uma forma peculiar de razão. Espaços sociais que são entendidos como "medium linguístico, isto é, a comunicação linguística voltada ao entendimento e ao consenso: é a razão comunicativa" (SIEBENEICHLER, 2003, p. 66). Habermas, dessa forma, amplia a noção de democracia para os espaços sociais além do espaço de debate político. Sua teoria implica em uma sociedade democrática, com a presença de uma espécie de cidadão ativo. Leonardo Avritzer ressalta esta característica na teorização de Habermas:

\footnotetext{
A obra habermasiana supõe uma dimensão comunicativa e interativa na qual os atores sociais, através da utilização da linguagem, participam de um debate crítico-racional acerca da organização normativa e política da sociedade em que eles vivem. Desse modo, o autor adota uma visão do processo político nas sociedades modernas de acordo com o qual o substrato normativo da política implica a procedimentalização da democracia em nível societário (AVRITZER, 2016, p. 46, 47).
}

Sem adotar uma postura teórica radical (no sentido de rejeitar o capitalismo), Habermas indica a possibilidade de espaços sociais impregnados de relações comunicativas. Então são espaços sociais que são pensados de forma diversa. Em primeiro lugar há espaços no qual prepondera a reificação, como na economia ou no estrato burocrático; em outros casos, o pensador alemão lança a ideia (amparando-se em Mead) de que no capitalismo há a possibilidade da existência de espaços nos quais "os participantes da interação podem dispor intencionalmente [de significados simbólicos]" (HABERMAS, 2012, p. 216).

Habermas ressalta que nesta nova postura teórica - que ele qualifica de teoria da 
comunicação - os atores "orientam suas ações pelas próprias interpretações da situação". Nos dois modelos (o "mundo da vida" e o "sistema"), há uma problemática sociológica que advém de Durkheim e que implica nas categorias de "integração social" e dos "níveis de diferenciação do sistema". Assim, de forma subjetiva, o mundo da vida procura auxiliar em uma forma de pensar na qual se se prioriza o "agir orientado pelo entendimento"; já na forma objetiva, ocorre "a problemática da reificação" em espaços com a intensa presença do capital.

Eis, então, que na razão comunicativa não há (como na razão instrumental) uma "autopreservação obcecada". Para Habermas (2012, p. 684), a razão comunicativa é entendida, desta forma: “(...) um mundo da vida simbolicamente estruturado que se constitui nas realizações interpretativas de seus participantes e só se reproduz por meio do agir comunicativo". Otimismo ante uma modernidade que inaugura novos espaços de entendimento. Por isso ele se refere, nos dias atuais, a uma persistência de uma "perspectiva utópica de conciliação e liberdade". Na socialização dos indivíduos por meio da comunicação linguística há essa possibilidade de uma nova racionalidade. É desta perspectiva que a teoria do agir comunicativo ensaia uma resposta satisfatória à "problemática da reificação".

Como se pode averiguar, o conceito de entendimento é fundamental na teoria habermasiana. É como se houvesse espaços sociais ainda não preenchidos pelo ideário de conteúdo democrático. São espaços no qual o consenso é possível e que podem ser compreendidos como um "entendimento comunicativo" da linguagem. Na apreciação de Flávio Siebeneichler (2003), o entendimento em Habermas se dá através da razão e do argumento. Na pretensão de validade do falante, há quatro elementos constitutivos: 1) Uma pretensão de inteligibilidade; 2) Uma pretensão cognitiva que indica o grau de "verdade" no conteúdo da mensagem; 3) A pretensão de correção que implica a reflexividade; e, 4) A pretensão de sinceridade e autenticidade. Esses elementos devem estar presentes, pois a pretensão (do agente de fala) será objeto de crítica, fato que deve ser considerado "normal":

O discurso visto como argumentação constitui um tipo de fala no qual os participantes tematizam pretensões de validade criticáveis, tentando resgatá-las através de argumentos que contêm "razões". $\mathrm{O}$ argumento constitui, pois, uma manifestação ou comportamento racional, que é criticável e, portanto, corrigível, podendo ser melhorado sempre que se descobrem os erros (SIEBENEICHLER, 2003, p. 97).

É como se tivéssemos em um espaço político no qual o confronto se transforma na própria natureza das relações. Mas o homem de consenso não é um ente partidário, ao estilo dos embates políticos do parlamento, por exemplo. Sua pretensão argumentativa deve ser justificada; Siebeneichler, com propriedade, acentua que "os argumentos" devem "ser avaliados ou pesados quanto à sua força consensual, isto é, com relação à sua capacidade de obter o consenso fundamental racionalmente" (SIEBENEICHLER, 2003, p. 101). Então, o ato de se questionar uma proposição é inerente ao espaço de entendimento, assim como a revisão de minhas pretensões de verdade. O critério de verdade deixa de ser algo transcendente ou mesmo de caráter tradicional. É "verdade" o conteúdo que resulta do "consenso obtido através da argumentação discursiva", na interpretação de Siebeneichler. 
Já a razão comunicativa no espaço escolar implica em uma remodelação dos vários papéis desempenhados pelos agentes. Ela torna possível, também, uma nova abordagem sobre o saber ensinado e o processo de aprendizagem. No modelo tradicional Iluminista, há a intenção de que o educando incorpore uma estrutura de saber através de um esquema de sanção (reprovação, notas, etc.). O educando que não participa deste jogo é considerado um transgressor. No fundo é o poder do saber (científico) que se utiliza da educação para a reprodução de sua estrutura de visão de mundo.

Já no modelo pragmático da razão comunicativa a pretensão de validez do conhecimento escolar é criticável. Aqui, visualiza-se uma questão: como agir em um espaço escolar compreendido como espaço de entendimento. O saber não pode ser mais imposto, mas argumentado; assim, deve haver neste jogo de argumentações uma simetria. O educando não pode estar inferiorizado, simplesmente por se achar em uma situação de aprendizagem. Habermas comenta das "relações complementares e simétricas" dos espaços de entendimento. Por isso o emergir de uma "autoridade intersubjetiva de uma vontade coletiva (...)" (HABERMAS, 2003, p. 194). Ela é uma forma de autoridade inédita, democraticamente erigida através da ação comunicativa. Nesse sentido, apagam-se dois extremos: o primeiro, como poder de saber na figura do professor-censor; segundo, os possíveis preconceitos dos educandos provindos do mundo da vida. Aqui, compreende-se melhor a afirmação de Henri Bergson em Duração e simultaneidade: "Os preconceitos desaparecem ou ao menos se enfraquecem quando submetidos à reflexão" (BERGSON, 2006, p. 198).

Aqui já se vislumbra a forma de aprendizado segundo a razão comunicativa. Os valores sócio-cognitivos necessitam ser reorganizados; eles passam a ser "reflexivamente examinados" (HABERMAS, 2003, p. 196). A razão comunicativa através do "entendimento mútuo linguístico" ensina a prática da compreensão, bem como a uma boa deliberação. Os princípios (que guiam nossas ações) devem ser reflexivamente pensados através do entendimento mútuo.

Habermas nos mostra o objetivo desta aprendizagem: validez normativa; autonomia e reflexividade. Assim, de um mundo centrado no sujeito, forma-se "uma compreensão de mundo completamente descentrada (...)" (HABERMAS, 2003, p. 203). O pensador alemão crê que a razão comunicativa desempenha a função de desfalecer a "força normativa do factual".

Observa-se, neste caso, a importância da qualidade (democrática) do espaço escolar. No pragmatismo, esse "ensaio" escolar é fundamental para se gerar uma personalidade democrática. A escola não ensina só os conteúdos científicos; ela deve ser capaz de formar um estilo de indivíduo democrático. Na lição pragmática, por meio da educação, "uma sociedade pode ensinar aos seus novos membros maneiras de resolver problemas concretos que Ihes advém, tanto na esfera da cultura e da ciência, quanto na moralidade e da política" (CASAGRANDE, 2016, p. 394). São temas que envolvem problemáticas importantes da sociedade. Elas se transformam em "situações de aprendizagem" que desafiam o educando; temas que são auxiliados pela "ação mediadora do educador" (CASAGRANDE, 2016, p. 395).

Então, o educando crítico nasce quando "o mundo dos estados de coisas existentes é teorizado, o mundo das relações ordenadas de maneira legítima é moralizado" 
(HABERMAS, 2003, p. 195). Só assim há a possiblidade do senso de justiça, fundado em bons princípios. Eles foram linguisticamente argumentados e passaram pelo teste dos "melhores argumentos".

\section{Considerações finais}

O pragmatismo através de suas objeções ao racionalismo apresenta uma nova abordagem sobre a aprendizagem. Uma das tarefas do pragmatismo é remover o poder de saber do racionalismo; a denominada pedagogia tradicional (que persiste em nossas instituições educacionais) faz parte de um amplo movimento que nasce no século XVIII. Ela se efetiva após a secularização do Estado e a configuração de um novo paradigma educacional fundado na ciência moderna. Isto é bem nítido no Rapport sur l'instruction publique, obra de 1792 de Condorcet. No comentário de Mario Manacorda, "Condorcet sustentava a necessidade de uma instrução para todo o povo, aos cuidados do Estado e inspirada num laicismo absoluto (...)" (MANACORDA, 1992, p. 250).

$\mathrm{Na}$ crítica de Richard Rorty (1988) a este modelo lluminista, o "representacionismo" é esta forma de conhecimento engendrada nos séculos XVII e XVIII. Para Rorty, neste último modelo o sujeito de conhecimento se traduz como uma espécie de "criança", ou seja, "portador de uma tendência à imitação" (DAZZANI, 2000, p. 19). Daí por que no pragmatismo há esta exigência de que haja a "reelaboração dos conteúdos" (DAZZANI, 2000, p. 13). Através da interpretação de Maria Dazzani da obra de Rorty, A filosofia e o espelho da natureza (1988), se evidencia as objeções à "epistemologia do espelho". Rorty nos apresenta o termo "redescrição" que pode ser aplicado ao ambiente educacional. Aqui, o educando realiza "novas descrições [que] podem reorientar, de um modo mais satisfatório, aquilo que vive como insatisfação, sofrimento, expandindo a capacidade de ser feliz" (DAZZANI, 2000, p. 32).

Foi através de John Dewey que o pragmatismo atinge o campo educacional na denominada Escola Nova. A reviravolta propiciada pelo pragmatismo implica em uma nova representação sobre a "verdade". Como enfatiza Barbara Smith, no pragmatismo "o sentimento de verdade é produzido" (SMITH, 2002, p. 68). Assim, para que esta "verdade" adquira significado é preciso "fazer-a-verdade", na expressão de Smith. Dessa forma, mais que uma simples técnica de aprendizagem, o construtivismo implica em uma nova postura epistemológica. Deve-se abandonar as ideias clássicas de "verdade e conhecimento" (SMITH, 2002, p. 72). Isto porque se almeja, antes de tudo, conhecer no educando as "condições particulares existentes", sua situação na qual a razão pode ser pensada. Isto explica o motivo de Barbara Smith indicar as "narrativas vívidas" que expressam tal situação de vida do educando. É nesse ambiente de reconstituição que o conhecimento como "verdade" pode ter uma "contra-argumentação": ao se remover o poder de saber da prática educacional, o educando só se apresenta como sujeito de conhecimento se há este espaço de liberdade.

$\mathrm{Na}$ perspectiva pedagógica de John Dewey, o ativismo no educando adquire significado (educativo) em um campo de experiência (DEWEY, 2011, p. 91). Por isso a ênfase na reconstrução do conhecimento objetivando uma "atitude indagadora, buscadora, 
investigadora" (Cf. DEWEY, 2007); tal postura deve estar acompanhada de um pensar sobre os pressupostos que propiciam tais atitudes. Na interpretação de Rogério Hermes sobre o pensar-educar em Dewey, a educação deve propiciar aos educandos um "modo crítico e criativo, o acesso aos conhecimentos produzidos no passado e reconstruí-los como se fossem parte de sua própria experiência (...)" (FÁVERO; TONIETO, 2011, p. 233). E só se atinge este estado indicado por Dewey - dúvida, perplexidade e dificuldade - se executarmos uma prática pedagógica na qual o conhecimento seja reconstruído em uma performance compreendida como experiência.

\section{Referências}

AVRITZER, Leonardo. A moralidade da democracia: ensaios em teoria habermasiana e teoria democrática. São Paulo: Perspectiva, 2016.

BERGSON, Henri. Duração e simultaneidade: a propósito da teoria de Einstein. Tradução de Claudia Berliner. São Paulo: Martins Fontes, 2006.

BOLZANI FILHO, Roberto. Acadêmicos versus pirrônicos. São Paulo: Alameda, 2013.

CASAGRANDE, Cledes A. Interacionismo simbólico, formação do self e educação: uma aproximação ao pensamento de G. M. Mead. Educação e Filosofia. Vol. 30, n, 59, p. 375-403, 2016. Disponível em: http://www.seer.ufu.br/index.php/EducacaoFilosofia/article/ view/24821. Acesso em: 1 junho 2010.

DAZZANI, Maria V. M. Educação e pragmatismo: uma interpretação de Richard Rorty. Dissertação de Mestrado. Salvador. Universidade Federal da Bahia. Faculdade de Educação (Programa de Pós-graduação em Educação), 120 p., 2000. Disponível em: https://repositorio.ufba.br/ri/bitstream/ri/30361/3/Maria\%20Virg\%C3\%ADnia\%20 Machado\%20Dazzani.pdf. Acesso em 1 jun. 2020.

DESCARTES, René. Discurso do método. Tradução de Elza M. Marcelina. São Paulo: Editora Ática, 1989.

DEWEY, John. Experiência e educação. Tradução de Renata Gaspar. Petrópolis: Editora Vozes, 2011.

DEWEY, John. Democracia e educação. Tradução de Roberto Cavallari Filho. São Paulo: Editora Ática, 2007.

FÁVERO, Altair A.; TONIETO, Carina (Orgs). Leituras sobre John Dewey e a educação. Campinas: Marcado de Letras, 2011.

FLAUBERT, Gustave. Madame Bovary. Tradução de Mario Laranjeira. São Paulo: Penguin Classics Companhia da Letras, 2016.

GEYMONAT, Ludovico. Galileu Galilei. Tradução de Eliana Aguiar. Rio de Janeiro: Editora Nova Fronteira, 1997.

HABERMAS, Jürgen. Consciência moral e agir comunicativo. $2^{\text {a }}$ Ed. Tradução de Guido A. de Almeida. Rio de Janeiro: Tempo Brasileiro, 2003.

HABERMAS, Jürgen. Teoria do agir comunicativo II: sobre a crítica da razão funcionalista. Tradução de Flávio B. Siebeneichler. São Paulo: wmf Martins Fontes, 2012. 
JAMES, William. Pragmatismo e outros ensaios. Traduzido por Jorge C. da Silva. Rio de Janeiro: Lidador, 1967.

MANACORDA, Mario A. História da educação: da Antiguidade aos nossos dias. $3^{a}$ Ed. Tradução de Gaetano Lo Monaco. São Paulo: Cortez Editora; Editora Autores Associados, 1992.

PAVIANI, Jayme. Filosofia e método em Platão. Porto Alegre: EDIPUCRS, 2001.

PLATÃO. Fedro (Texto Bilingue). Tradução de Carlos A. Nunes. Belém: Editora da UFPA, 2011.

RORTY, Richard. Filosofia como política cultural. Tradução de João C. Pijnappel. São Paulo: Martins Martins Fontes, 2009.

RORTY, Richard. A filosofia e o espelho da natureza. Tradução de Jorge Pires. Lisboa: Dom Quixote, 1988.

SIEBENEICHLER, Flávio B. Jürgen Habermas: razão comunicativa e emancipação. $4^{a}$ Ed. Rio de Janeiro: Tempo Brasileiro, 2003.

SMITH, Barbara H. Crença e resistência: a dinâmica da controvérsia intelectual contemporânea. Tradução de Maria E. m. Sayeg. São Paulo: Editora da UNESP, 2002.

SPINELLI, Miguel. Bacon, Galileu e Descartes: o renascimento da filosofia grega. São Paulo: Edições Loyola, 2013.

\section{Correspondência}

Dagmar Manieri - Rua Bela Vista, 673, São João, CEP: 77807-040, Araguaína, Tocantins, Brasil.

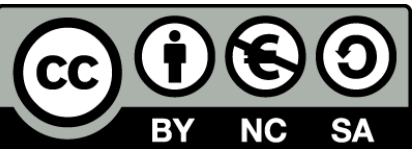

This work is licensed under a Creative Commons Attribution-NonCommercial 4.0 International (CC BY-NC 4.0) 